\title{
Map Data Representation for Indoor Navigation by Blind People
}

\author{
Watthanasak Jeamwatthanachai, Mike Wald, Gary Wills \\ School of Electronics and Computer Science, University of Southampton \\ Southampton, United Kingdom, SO17 1BJ
}

\begin{abstract}
A map is a basic element that is used for indoor and outdoor navigation which helps people find information about locations, landmarks, and routes. By the use of GPS, outdoor travelling is easier with free maps e.g. Google Maps providing geographic information during navigation. For indoors, indoor spatial information is not much informed by Google Maps and neither do commercial products that are working on indoor navigation systems. Thus, the lack of information and detail of buildings may not cause so many problems if it is used by sighted people. For visually impaired people, it causes a lot of problems due to a lack of information and detail about interior of the buildings. This leads to the research question of finding an appropriate framework for map data representation for constructing indoor maps aimed to promote indoor navigation by visually impaired people, as well as by robots and autonomous systems. Prior to the design of the framework, we design the framework with eleven components, extending seven components of the previous study by a further four covering the parameters of disability. The framework has been designed with a reference model where each layer of which is responsible for a different function. Using this map data representation of indoor spaces, many applications can be extended to provide a range of indoor-based applications. For example: indoor navigation by people with disabilities, robots and autonomous systems, security and surveillance, and context and spatial awareness.
\end{abstract}

\section{Introduction}

In 2014, the World Health Organization ${ }^{1}$ (WHO) estimated the number of visually impaired people (VI) at around 285 million worldwide, of which 39 million are blind, and 246 million have low vision. However, WHO has classified types of vision into four levels: normal vision, moderate visual impairment; severe visual impairment; and blindness. Being lack of sight, apparently, life is more difficult as it directly affects to any activities, especially the activities that requires an ability to

\footnotetext{
${ }^{1} \mathrm{WHO}$ | Visual Impairment and Blindness -

http://www.who.int/mediacentre/factsheets/fs282/en/
}

navigate. Hence, navigating through cities or buildings by themselves is too difficult. The study has said that for $80-90 \%$ of visually impaired people have spent their daily life inside buildings [1] due to the lack of vision. To navigate independently, orientation and mobility $(\mathrm{O} \& \mathrm{M})$ program is essential to visually impaired people, teaching safe, efficient, and effective travel skills. In this program, visually impaired people are taught how to use a common tool e.g. a white cane and sensory compensation to sense their surrounding environment which is an important part of forming a mental map, aka a mind's eye. Despite the facts that, independently walking through the cities or buildings is still difficult as a lot of problems and problems is encountered, for example obstacles, noise, and other barriers which directly affect their daily activities and navigation [2] indoors and outdoors.

Even though a global positioning system (GPS) has brought huge benefits to an outdoor navigation, accuracy in estimating positions inside buildings is unacceptable due to its limitations. Hence, an indoor positioning system (IPS) has been invited in various sensors technologies providing an ability to estimate positions indoors which is used in indoor navigation system (INS) shown in the commercial products (e.g. indoo.rs, Wifarer, etc.). These systems have come up with a general map where information about layout of buildings are provided in 2D used in route-finding and planning processes. However, general maps would not be enough to help these people to navigate inside the buildings due to the need of extra information such as landmarks, obstacles, hazards, etc. As a matter of fact, indoor spatial information is the most important in terms of promoting indoor navigation by visually impaired people.

To design the maps that can be solving all of the problems and challenges, we design the map data representation based on our previous study which was designed for autonomous system [3]. Design for visually impaired people, it is essential to understand how people behave when navigate inside the buildings, and to investigate what type of information that are useful to provide a greater independent navigation indoors.

To design the map data representation, in this paper we design by prior a numerous research and 
studies shown in Section 2, and later discuss about problems and challenges in Section 3. Map data representation framework will be revealed with definitions of its components in Section 4. An overview of the map data representation framework is presented in Section 5, including its potential application and extensions.

\section{Related Work}

To design the map data representation that is able to solve the problems and challenges, it is paramount to develop it by prior numerous research and studies regarding indoor navigation by visually impaired people, indoor navigation systems, and indoor maps.

\subsection{Blindness and Sensory Compensation}

For visually impaired people, being able to connect with social activities and having a social life are difficult tasks due to the physical challenge that it makes them feel left out of activities. Vision loss has significant impacted visually impaired people in most of the activities that are essential to their development A lot of problems and challenges have impacted directly to these people in most of their activities which are usually related to navigation. Therefore, travelling without vision is obviously challenging for congenital blind, adventitious blind and blindfolded sighted people [4].

Lacking vision, other senses may come into play in the role of complementary information to fill the gap of perception, and is called sensory compensation [5]. By concentrating on residual senses, people can sense and learn the surrounding environment through multi-sensory channels [6]. Through O\&M and multi-sensory channels, learning surrounding environment is another necessary process that makes visually impaired people familiar with the spaces. To learn and familiarize the spaces, visually impaired people usually learn it by using the use of landmarks, aka 'navigational cues' which are used in a construction of the mental map.

\subsection{Indoor Navigation by Visually Impaired People}

Numerous problems and challenges have been found while navigating outdoors [2], while travelling inside, especially, unfamiliar spaces and buildings is even harder due to difficulties e.g. (ground, body, and head) obstacles, crowd, and slippery floor. Learning a new environment like hospitals, department stores or any large and complex buildings is more difficult which cause a number of difficulties in navigating indoors, due to the lack of navigational cues and accessibility information [7]. Therefore, it is very hard to visually impaired people to decide the way to go in order to reach the destination in such complex and crowded environments [8].

\subsection{Assistive Technology}

Thanks to advances in technology, the role of the smartphone has come into play in various industries, even helping with disability and accessibility, with significant features such as VoiceOver ${ }^{2}$, which is a screen reader built into the system enabling visually impaired people to access information via spoken descriptions. TapTapSee ${ }^{3}$ is a mobile application that enabling the camera to identify objects and speak out loud to the user. Yet another example is BlindSquare $^{4}$, an accessible navigation for indoors and outdoors providing information about surround environment, points of interest, street intersections and other to visually impaired people through audible feedback.

A lot of wearable computing devices have been developed while the first was invented [9] by the use of GPS and geographic information system (GIS) and use ultrasound to detect obstacles reporting to user via headset while walking. Later on, a lot of wearable computing devices have adopted this idea such as 3D soundscape ${ }^{5}$, a device that use GPS and smartphone to find orientation outdoors, and Alice band $^{6}$, another wearable computing devices adopted the RFID providing information about buildings and objects to help people navigate inside the buildings.

\subsection{Indoor Navigation Systems}

Even though GPS is the most powerful tool widely used for navigation these days, its performance is even weaker when deployed inside buildings due to its cha-racteristics and limitations. To fill the gap, researchers have studied IPS in various techniques such as RFID [10], Radio Map approaches (Bluetooth [11], Wi-Fi [12]), UltraWideband [13]), Ultrasound [14], Inertia Sensor [15], Optical [16], and Visible Light [17]. Many reasons have led into this subject since many applications could take this advantage of IPS such as indoor navigation systems for robots and autonomous systems.

\footnotetext{
${ }^{2}$ Apple VoiceOver http://www.apple.com/uk/accessibility/ios/voiceover/ ${ }^{3}$ TapTapSee - http://www.taptapseeapp.com

${ }^{4}$ BlindSqure - http://blindsquire.com/

${ }^{5}$ Microsoft 3D Soundscape - http://tnw.to/e4kQ1

${ }^{6}$ Microsoft Alice band http://tech.firstpost.com/news-analysis/microsoftsalice-band-help-blind- people-step-crowded-places227395.html
} 
Table 1. Problems and challenges that visually impaired people have experienced when navigating inside unfamiliar spaces and buildings, including the limitations of indoor navigation technologies and maps for visually impaired people

\begin{tabular}{|c|c|c|}
\hline $\begin{array}{l}\text { Problems and } \\
\text { Challenges }\end{array}$ & Problem & Solutions \\
\hline $\begin{array}{l}\text { Unfamiliar } \\
\text { places }\end{array}$ & $\begin{array}{l}\text { Difficulties in navigating inside the unfamiliar places which are } \\
\text { usually large, complex, wide-open, full of crowd and noise, and } \\
\text { lack accessibility information. Guide dog may not be allowed in } \\
\text { some buildings, especially intensive care unit at the hospital. }\end{array}$ & $\begin{array}{l}\text { Sighted Guide } \\
\text { Accessible Map } \\
\text { (limited) }\end{array}$ \\
\hline $\begin{array}{l}\text { Barrier free } \\
\text { Information }\end{array}$ & $\begin{array}{l}\text { Difficulties in navigating inside buildings which lack } \\
\text { accessibility information such as tactile pavement, information } \\
\text { regarding stairs, escalator, drop-offs, room number and name, } \\
\text { etc. which are not usually provided. }\end{array}$ & $\begin{array}{l}\text { Sighted Guide } \\
\text { Accessible Map } \\
\text { (limited) }\end{array}$ \\
\hline $\begin{array}{l}\text { Map for Visually } \\
\text { Impaired People }\end{array}$ & $\begin{array}{l}\text { Information provided in a map, both commercial and public } \\
\text { service, is limited and not enough for visually impaired people. } \\
\text { To provide more confidence in navigation, objects and } \\
\text { accessibility information should be integrated into the map. }\end{array}$ & $\begin{array}{l}\text { Proposed } \\
\text { Framework }\end{array}$ \\
\hline $\begin{array}{l}\text { Indoor } \\
\text { Navigation } \\
\text { System }\end{array}$ & $\begin{array}{l}\text { No matter what indoor positioning techniques have been used in } \\
\text { the indoor navigation system, the map is the main part of the } \\
\text { navigation, which is usually proprietary and lacks information } \\
\text { required by visually impaired people. }\end{array}$ & $\begin{array}{l}\text { Proposed } \\
\text { Framework }\end{array}$ \\
\hline $\begin{array}{l}\text { Obstacle } \\
\text { Detection and } \\
\text { Avoidance }\end{array}$ & $\begin{array}{l}\text { Difficulties in detecting and dodging obstacles installed or } \\
\text { placed in the environment during navigation. }\end{array}$ & $\begin{array}{l}\text { Echolocation } \\
\text { Sensor: Ultrasound }\end{array}$ \\
\hline $\begin{array}{l}\text { Unpredictable } \\
\text { Obstacles }\end{array}$ & $\begin{array}{l}\text { Difficulties in detecting or receiving information regarding } \\
\text { unpredictable objects such as crowd, noise, etc. }\end{array}$ & Sensor: Camera \\
\hline
\end{tabular}

By cooperating with an indoor map, IPS is equipped with indoor spatial information which is providing features into the system. For example, route planning, navigation. Indoor maps introduced into the system, on the contrary, are usually plain, not well-described which is usually stored in forms of raster or vector graphic. Lack of details and complementary information of the spaces and buildings, this could cause a lot of problems when is used by visually impaired people.

\subsection{Maps and Data Representation}

Nowadays, the most important component used in navigation is a map which provides information about locations and routes to people. Most of the maps are usually available for outdoor travel, while indoors is another story the difficulties of providing information and detail of the buildings, which is important to the indoor navigation by visually impaired people [10]. Several studies and commercial products of indoor-based localization and navigation systems are mostly developed as standalone systems, and whose maps are designed in raster or vector graphic formats providing information of specific areas in the buildings. Google has also proposed a brand new indoor map platform, called Google Indoor Maps, a crowdsourcing model providing a feature that allows user to create 2D indoor map with a basic indoor information placed on top of Google Maps itself which is suitable for general purposes. Considering that, these features may not be enough and met the minimum requirements to deploy for running complicated tasks, for example a self-driven car, autonomous self-picking and item-finding at a warehouse, or even indoor navigation systems for visually impaired people which requiring further info-rmation. This information is paramount as to provide a free mobility used to promote indoor navigation capability such as the presence of objects, obstacles, transitions, and accessibility information.

Towards a construction of indoor maps, [19] [20] has proposed basic components: topographic, sensor and navigation used in the construction of indoor maps in a 3D geography. Influenced by [19] [20], the map data representation [3] was created for robots and autonomous system consisting of seven components categorized into five layers representing the buildings to cover all of the problems and challenges found in indoor navigation by robots and autonomous systems, excluding the case of visually impaired people. 


\section{Problems and Challenges}

The literature was reviewed in various field related to indoor navigation problems by visually impaired people, assistive technology, and indoor navigation systems. A lot of problems and challenges have been found in the literature. However, many solutions have been applied to solve the problems and challenges by using a wide range of technology and algorithms built into a variety of devices and systems, both low-tech devices (white cane, guide dog, and sighted people) and high-tech devices (wearable computing, smart canes, and indoor positioning systems).

Table 1 summarizes the problem and challenges that visually impaired people experience, solutions that have been applied, and also implies most of the problems and challenges could be solved if indoor spatial information is introduced. For these reasons, it is important to develop a map that can store essential information that can be used to help visually impaired people to have a greater independence in navigating inside the buildings where places are full of unfamiliar features.

\section{Map Data Representation Framework}

(L5) WAYFINDING
(L4) PATH
(L3) SENSOR
(L2) OBJECTS
(L1) FLOOR PLAN

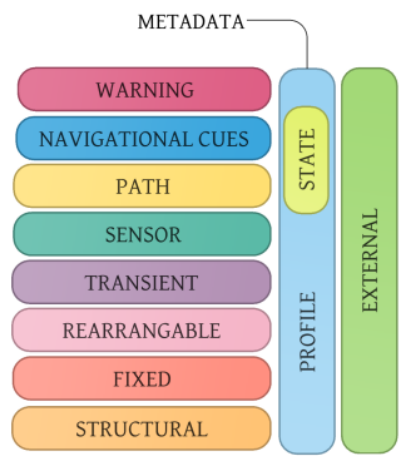

Figure 1. A conceptual framework for map data representation for indoor navigation by visually impaired people

In [3], the previous study has proposed that there were seven major components, extending three from [19], while there are five major components extended from [3] providing complementary information given into the systems in order to promote indoor navigation by visually impaired people. The first component is navigational cues which is information regarding the landmarks and other useful information provided to help people to have a greater independent navigation. The second component is warning information that provides information regarding hazards and area that people need to be more careful. The third and fourth components are profile and state representing detail and status of the objects placed inside the buildings and spaces. The last component is external providing information that impacts the indoor navigation by visually impaired people such as the weather and noise.

Considering the gap of technologies and previous studies, a framework of map data representation for indoor navigation by visually impaired people has been developed. As shown in Fig. 1, the framework is split into five layers consisting of eleven components, extending the seven components of [3], where three major components: profile, state, and external are not categorized into any of these five layers. Therefore, a conceptual framework of map data representation is proposed for promoting indoor navigation by visually impaired people to provide a greater independence. However, this also supports autonomous systems (e.g. self-driving vehicle and robotic) to have an ability to detect surrounded environments which is of use in any places. For example, self-driving vehicle that offering transportation facilities to people with disabilities in the airports and hospitals. To solve these problems, a reference model is designed, shown in Fig 2. For the definitions of each components are listed below:

Structural, the bottommost component represents the floor layout showing relationships between rooms and transition spaces (e.g. doors) for each floor inside the buildings, where each floor can be linked to other floor by the transition spaces (e.g. stairs, escalators, and lifts). This component also includes information about dimension, size, wall type, etc. This layer is compulsory as to provide information about structure of the building towards the construction of the spatial representation (e.g. indoor map) in 3D geography.

Fixed Objects, a component contains information about fixed objects that permanently installed inside the buildings e.g. furniture and transition objects like doors, stairs, escalators, and lifts. This component also encompasses information about barriers inside the buildings that impacted indoor navigation by visually impaired people, such as drop-offs, curbs, events, and restriction areas (e.g. construction and renovation areas). This component is important to visually impaired people as to provide information regarding landmarks which is useful for people when navigating inside the buildings with full of unfamiliar configuration. To classify the objects, a scale-based object classification will be provided and its examples in Section 4.2.

Rearrangeable Objects, this component contains information about the objects can be rearranged like furniture (e.g. table, chairs, waste bins) or other objects that remain in their position for a medium to 
long period of time, depending on a movability factor scaled in Fig. 3 and Table III. This component is help-ful as to provide information about random objects, which are accounted as navigation barriers, to visually impaired people to avoid the obstacles along the ways while navigating indoors. To classify the objects, a scale-based object classification will be provided and its examples in Section 4.2.

Transient Objects, a component contains information about the objects that can be rearrangeable, but last for a short period of time, for instance selfmoving objects (people, pet, and robots). This component is also helpful, providing information regarding random objects as accounted as navigation barriers to visually impaired people to avoid the obstacles along the ways while navigating indoors. This component is of use in promoting the indoor navigation by visually impaired people, and also used in terms of measuring indoor traffic, detecting objects, finding an appropriate route for visually impaired people, autonomous systems, and robots. To classify the objects, a scale-based object classification will be provided and its examples in Section 4.2.

Sensor, a special object that possess abilities of detecting events and/or sending out information to the spaces for specific purposes, for example: lighting, smoke detector, Wi-Fi, RFID, camera or CCTV, door switch sensor, and others. This component contains information about sensors installed inside buildings. This component is useful to visually impaired people and further development for visually impaired people such as indoor localization and navigation, obstacle detection, and security and surveillance.

Path, a component that contains information about the walkable area (e.g. hallways) and restriction area (e.g. emergency exit), enabling visually impaired people to know which area and path are approved for walking, depending on the situations. This component can be used as part of the route planning process in the indoor navigation systems, evacuation systems. Also, it is useful in the process of construction of accessible maps.

Navigational cues, a component contains markers and information regarding the cues that can be used to promote the indoor navigation by visually impaired people such as objects (e.g. edges and corners), areas (e.g. intersection), landmarks. Especially, information describes the transition spaces e.g. stairs: tread width, riser height, and depth width. This information is quite useful and important to visually impaired people to independently navigate inside the buildings with full of unfamiliar configuration.
Warning, this component contains warning markers and information about hazards that could happen to visually impaired people such as sharped edges, stairs and escalators, slippery surface, holes, drop-offs, and especially, glass doors and automatic sliding doors. This component is useful and important as to provide free mobility to visually impaired people while navigating inside the buildings where are full of unfamiliar configuration.

Profile, a component that contains a metadata of areas and objects placed or installed inside the spaces and buildings, including information about physical dimension, size, wall type, etc. This component also includes general information about building such as building profile, pre-visit information, etc.

State, a sub component working under the profile component that contains information about current state of the objects, especially transition spaces e.g. doors, elevators, escalators, and travellators. For example, door (e.g. "open", "closed"), escalator (e.g. "going up", "going down"), or lift (e.g., "going up", "going down", current floor).

External, a component that contains information to support and improve sensory compensation while navigating indoors. This type of information has potentially impacted indoor navigation capability by visually impaired people, such as light goes through windows, noise from rain, car horn, or construction outside the buildings. This component is of use to visually impaired people, especially person who is partial sighted that use light to detect orientation in wayfinding process.

\subsection{Reference Model}

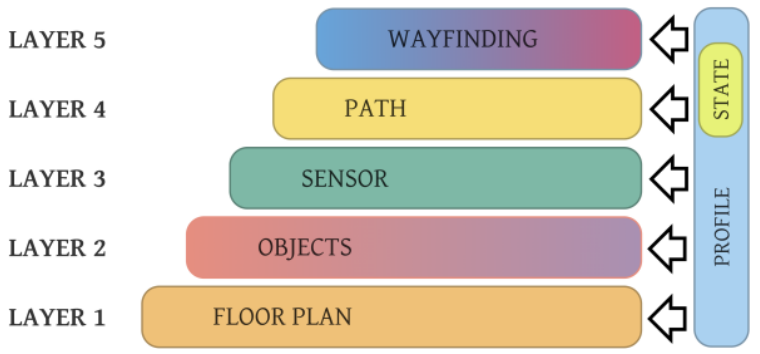

Figure 2. Reference model for map data representation architecture

Given the diagram (see Figure 1) and definitions, the layers in this framework are arranged in a reference model in terms of a design implication that indoor spatial information is represented by a collection of data and relationships mapping between layers in the reference model, shown in Figure 2. It is so obvious that the most important component of the map is layout and spaces connectivity. To visualize the buildings in 3D geography, the indoor spatial 
Table 2. Bottom Up Design of The Framework and Its Potential Applications

\begin{tabular}{|l|l|l|}
\hline \multicolumn{1}{|c|}{ Level } & \multicolumn{1}{|c|}{ Description } & \multicolumn{1}{c|}{ Applications } \\
\hline L5 - Wayfinding & $\begin{array}{l}\text { Navigational cues and } \\
\text { warning information }\end{array}$ & $\begin{array}{l}\text { Indoor Navigation for People with Disabilities, } \\
\text { Accessible Map (interactive) }\end{array}$ \\
\hline L4 - Path & Walkable areas and paths & $\begin{array}{l}\text { Indoor Navigation for Autonomous System } \\
\text { and Robotic, Route Planning }\end{array}$ \\
\hline L3 - Sensor & $\begin{array}{l}\text { Camera, Wi-Fi, RFID, } \\
\text { and others }\end{array}$ & $\begin{array}{l}\text { Indoor Positioning System, Network } \\
\text { Planning, Security and Surveillance, } \\
\text { Obstacle Detection and Avoidance, } \\
\text { Access Control }\end{array}$ \\
\hline L2 - Objects & $\begin{array}{l}\text { Fixed, Rearrangeable, and } \\
\text { Transient objects }\end{array}$ & $\begin{array}{l}\text { Floor Plan with Interior, } \\
\text { Spatial awareness, Accessible Map }\end{array}$ \\
\hline L1 - Structural & $\begin{array}{l}\text { Relationships of rooms, } \\
\text { spaces, entrances }\end{array}$ & $\begin{array}{l}\text { Floor Plan (a general indoor } \\
\text { map) }\end{array}$ \\
\hline
\end{tabular}

representation should be designed by first putting the floor plan layer (level 1) at the bottommost as a must. The objects layer combines as the second (level 2) layer representing the information of the objects installed inside the buildings and spaces, and so it the sensor layer (level 3) which is originally designed for the indoor positioning systems, In the framework, this layer is extended to have more types of sensor (e.g. camera, light, magneto, ultrasound, IR, smoke and heat detector, etc.) whose information can be utilized for various purposes such as security and surveillance, obstacles detection, and especially lighting that used to provide information about lighting for people who still has light perception. Level 4 is placed by the path layer providing information about walk-able area path that allow people for walking, while wayfinding layer (level 5) is placed on top in order to provide a free mobility and warning information about hazards and objects people need to be more aware while using e.g. escalators and stairs.

To provide a barrier free navigation indoors to visually impaired people, it is paramount to put information of all the objects that placed or installed inside the spaces and building which is consisting of two major components: profile and state which are not counted in any of five layers. Descriptions (or profile) and states of the objects are integrated into the map data representation simultaneously when compiling those five layers. In the reference model, external components may be included, depending on situations and weather information such as noise (car horn, raining, and construction), and light (sunny day).

Table 2 illustrates example of how each layer comes into play with the other layers to support future development. First, the bottommost layer (L1) is responsible for the construction of the floor plan of all floors in the building, also known as the general indoor map. Including objects (L2), the floor plan is equipped interior information using to increase spatial awareness to visually impaired people. Enhanced with the sensor information (L3), many applications can be extended, for example, Camera: obstacles detection and avoidance, and Wi-Fi: indoor positioning, and navigation systems. In the L4, walkable area and path is provided to satisfy the indoor navigation system features and to inform visually impaired people which area are approved for walking. Finally, wayfinding layer (L5) included into the spatial representation, maps will be of use for people with disabilities, providing free mobility information along during their navigation inside buildings.

\subsection{Objects Classification}

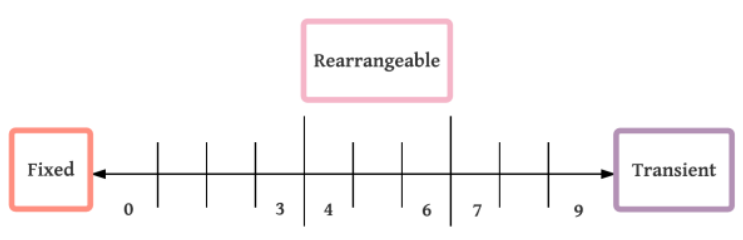

Figure 3. Scale based objects classification

In this section, the objects are classified into fixed, rearrangeable, and transient objects which are used in different purposes for promoting navigation indoors. In particular buildings like hospital, department store, and airport, objects like elevators and escalators are classified as fixed object installed inside the buildings and also have a transportation (moving) ability in order to move something from state or another state. This term could be confusing since moving objects like people are also considered as moving (transient) objects. To minimizing the 
confusion, terms of object and transportation object will be declared as follows:

1) Object is a representation of a physical object that can be everything that has surfaces and touchable. The objects can be split into three types of object by considering a movability factor

2) Super Object is a collection of the objects that collectively formed into one another object which is bigger than each one separately. For example, group of objects placed in the

\section{Applications and Extensions}

To increase the indoor spatial awareness, the map data representation framework has been designed in forms of the reference model, shown in Section 4.1, including examples of layers combined. This section describes how the framework comes into play in the future developments to cover all of the problem and challenges. By compiling all of layers together, the buildings are logically visualized in a 3D geography, providing all of the information that will be of use for promoting indoor navigation by robots, autonomous systems, and especially visually

Table 3. Objects Classification: scaling definition and examples

\begin{tabular}{|c|c|c|c|}
\hline Type & Scale & Definition & Example \\
\hline \multirow{4}{*}{ Fixed Objects } & 0 & $\begin{array}{l}\text { Permanently come with the building, } \\
\text { cannot be changed }\end{array}$ & $\begin{array}{l}\text { Stair, Sidewalk, Pavement/ Drop- } \\
\text { off, Sloped floor, Curb/ Hole on the } \\
\text { ground }\end{array}$ \\
\hline & 1 & $\begin{array}{l}\text { Installed in the building, impossible or } \\
\text { hard to uninstall }\end{array}$ & $\begin{array}{l}\text { Elevator, Escalator, Travellator/ } \\
\text { Fence }\end{array}$ \\
\hline & 2 & $\begin{array}{l}\text { Installed in the building, can be } \\
\text { removable. }\end{array}$ & $\begin{array}{l}\text { Floor-mount furniture/ Wall-mount } \\
\text { furniture Built-in furniture/ } \\
\text { Bathroom stuffs (basin, shower } \\
\text { bowl, toilet) }\end{array}$ \\
\hline & 3 & $\begin{array}{l}\text { Temporary installed in the building } \\
\text { with specific period of time. }\end{array}$ & $\begin{array}{l}\text { Construction area/ Building } \\
\text { renovation }\end{array}$ \\
\hline \multirow{3}{*}{$\begin{array}{l}\text { Rearrangeable } \\
\text { Objects }\end{array}$} & 4 & $\begin{array}{l}\text { Large object that is difficult to } \\
\text { reposition due to a physical appearance. }\end{array}$ & Refrigerator, freezer (Family size) \\
\hline & 5 & $\begin{array}{l}\text { Medium object that is sometime } \\
\text { difficult to reposition. }\end{array}$ & $\begin{array}{l}\text { Table, Chair/ Small refrigerator, } \\
\text { Freezer Personal Computer, } \\
\text { Workstation/ Office plant }\end{array}$ \\
\hline & 6 & $\begin{array}{l}\text { Small object that is easy to reposition or } \\
\text { detachable }\end{array}$ & $\begin{array}{l}\text { Litter-bin/ Rug/ Portable Equipment } \\
\text { Fire extinguisher }\end{array}$ \\
\hline \multirow{3}{*}{$\begin{array}{l}\text { Transient } \\
\text { Objects }\end{array}$} & 7 & Unintentional or accidental object & Wet floor, Litter \\
\hline & 8 & Objects created by schedules & Cleaning area \\
\hline & 9 & Self-moving objects & $\begin{array}{l}\text { People, Pet/ Robotic, Autonomous } \\
\text { System }\end{array}$ \\
\hline
\end{tabular}

construction and event areas.

3) Transition Object is an object that come up with an ability to transfer objects from one state to another state which is usually classified as fixed type of object e.g. escalators, travellators, and lifts.

4) Self-Moving Object is an object with movability that can be moved by itself without external force e.g. people, animals, autonomous systems and robots. impaired people. This is also useful for indoor-based systems as shown in Figure 4 presenting potential applications and extensions for the future developments. For instance, interactive accessible map, indoor navigation for people with disabilities, context awareness system, security and surveillance. This approach could also be applied to robots and autonomous systems in various buildings such as airports, museums, hospitals, universities, or other buildings. 


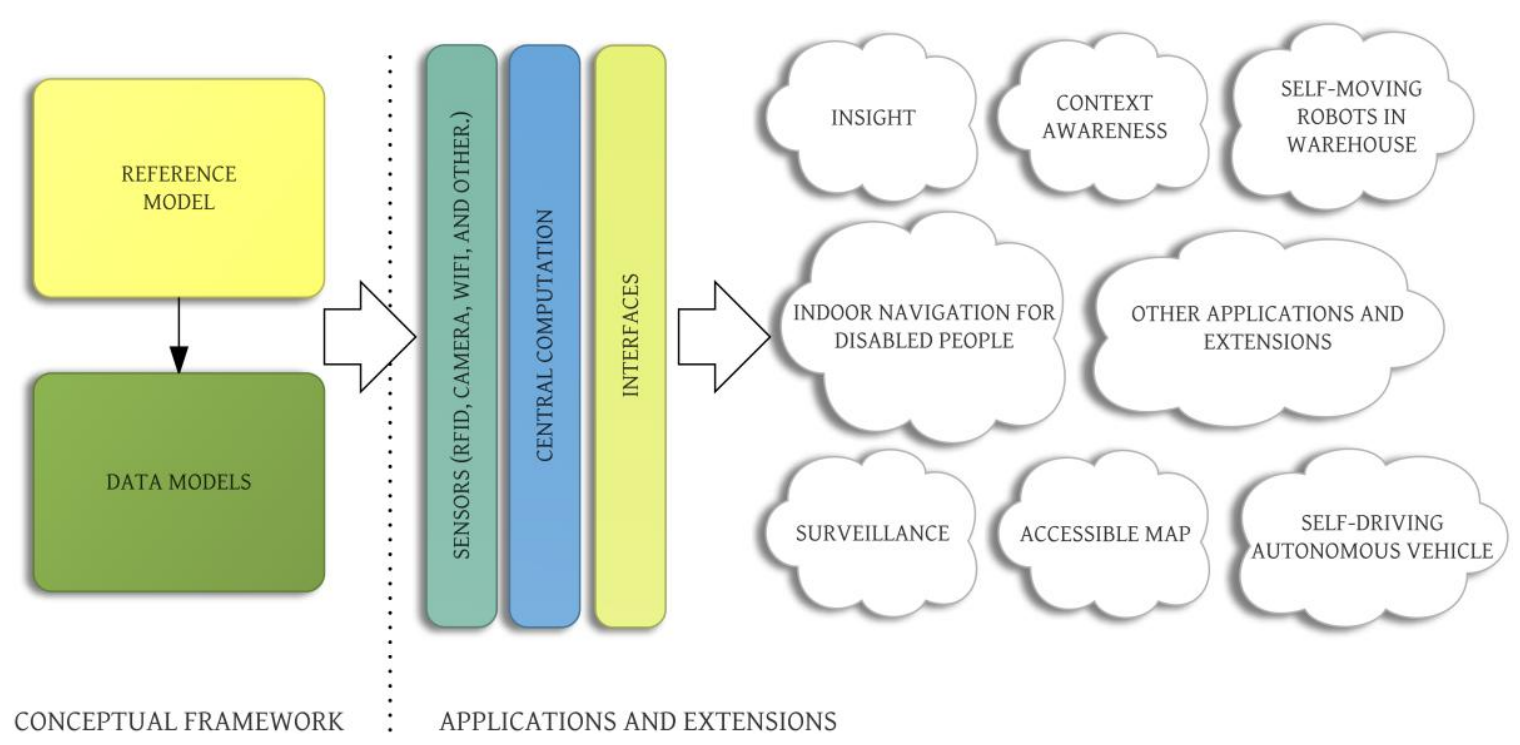

Figure 4. Applications and extensions might have potentially adopted the use of map data representation

\section{Conclusion}

Considering the problems and challenges found in the literature and commercial products regarding the indoor navigation by visually impaired people in the unfamiliar spaces and buildings, we found that most of the buildings have lack of accessibility, and maps themselves have also lack of information and detail of objects or obstacles that are usually placed randomly, inside the spaces and buildings. For these reasons, visually impaired people have been suffering while navigating through every unfamiliar space due to the physical challenge making them not able to navigate by themselves which leads to asking of assistances from sighted people.

A map, however, is the one of the basic component that people usually prefer to use when finding route to the destination, while indoor navigation systems have used it, as maps provide indoor spatial information. However, a general map may not satisfy the minimum requirements by visually impaired people since extra information required. To cover these problems, the map data representation framework was design with eleven components categorized into five layers which each component is responsible for different purposes. To promote indoor navigation by visually impaired people, three components of object (fixed, rearrangeble, and transient) were introduced. Navigating with free mobility and barrier free, two components were also included in the map data framework, providing information regarding navigation cues and warning about hazards and objects that people need to be more aware while approaching or using them.

\section{References}

[1] K.-J. Li and J. Lee, "Indoor spatial awareness initiative and standard for indoor spatial data" in Proceedings of IROS 2010 Workshop on Standardization for Service Robot, vol. 18, 2010.

[2] L. Zeng, "A Survey: Outdoor Mobility Experiences by the Visually Impaired". In Mensch \& Computer 2015-Workshopband, 2015, pp. 391-397.

[3] W. Jeamwatthanachai, M. Wald, and G. Wills, "Map data representation for indoor navigation," in 2016 International Conference on Information Society ( $i$ Society). IEEE, 2016, pp. 91-96.

[4] L. Picinali, A. Afonso, M. Denis, and B. F. Katz, "Exploration of architectural spaces by blind people using auditory virtual reality for the construction of spatial knowledge," International Journal of HumanComputer Studies, vol. 72, no. 4, pp. 393-407, 2014.

[5] Z. Cattaneo and T. Vecchi, Blind vision: the neuroscience of visual impairment. MIT Press, 2011.

[6] S. Millar, Understanding and representing space: Theory and evidence from studies with blind and sighted children. Clarendon Press/Oxford University Press, 1994.

[7] M. A. Williams, A. Hurst, and S. K. Kane, "Pray before you step out: describing personal and situational blind navigation behaviors," in Proceedings of the 15th International ACM SIGACCESS Conference on Computers and Accessibility. ACM, 2013, p. 28.

[8] A. Ganz, J. Schafer, S. Gandhi, E. Puleo, C. Wilson, and M. Robertson, "Percept indoor navigation system for the blind and visually impaired: architecture and experimentation," International journal of telemedicine and applications, vol. 2012, p. 19, 2012.

[9] A. S. Helal, S. E. Moore, and B. Ramachandran, "Drishti: An integrated navigation system for visually impaired and disabled," in Proceeding of the 5th International Symposium on Wearable Computers, 2001. IEEE, 2001, pp. 149-156.

[10] A. Ganz, J. Schafer, S. Gandhi, E. Puleo, C. Wilson, and M. Robertson, "Percept indoor navigation system for the blind and visually impaired: architecture and 
experimentation," International journal of telemedicine and applications, vol. 2012, p. 19, 2012.

[11] F. Subhan, H. Hasbullah, A. Rozyyev, and S. T. Bakhsh, "Indoor positioning in bluetooth networks using fingerprinting and lateration approach," in Information Science and Applications (ICISA), 2011 International Conference on. IEEE, 2011, pp. 1-9.

[12] D. Vasisht, S. Kumar, and D. Katabi, "Decimeterlevel localization with a single wifi access point," in 13th USENIX Symposium on Networked Systems Design and Implementation (NSDI 16), 2016, pp. 165-178.

[13] Z. Sahinoglu, S. Gezici, and I. Guvenc, "Ultrawideband positioning systems," Cambridge, New York, 2008.

[14] C. Medina, J. C. Segura, and A. De la Torre, "Ultrasound indoor positioning system based on a low-power wireless sensor network providing subcentimeter accuracy," Sensors, vol. 13, no. 3, pp. 3501-3526, 2013.

[15] R. Harle, "A survey of indoor inertial positioning systems for pedestri- ans," Communications Surveys \& Tutorials, IEEE, vol. 15, no. 3, pp. 1281-1293, 2013.

[16] M. Serra ̃, J. M. Rodrigues, J. Rodrigues, and J. H. du Buf, "Indoor localization and navigation for blind persons using visual landmarks and a gis," Procedia Computer Science, vol. 14, pp. 65-73, 2012.

[17] N. U. Hassan, A. Naeem, M. A. Pasha, T. Jadoon, and C. Yuen, "Indoor positioning using visible led lights: A survey," ACM Comput. Surv., vol. 48, no. 2, pp. 20:1-20:32, Nov. 2015.

[18] R. Hansen, B. Thomsen, L. L. Thomsen, and F. S. Adamsen, "Smartcampusaau-an open platform enabling indoor positioning and navigation," in Mobile Data Management (MDM), 2013 IEEE 14th International Conference on, vol. 2. IEEE, 2013, pp. 33-38.

[19] K. J. Li and J. Y. Lee, "Basic concepts of indoor spatial information candidate standard indoorgml and its applications," Journal of Korea Spatial Information Society, vol. 21, no. 3, pp. 1-10, 2013.

[20] J. Lee, K. Li, S. Zlatanova, T. Kolbe, C. Nagel, and T. Becker, "OgcQR indoorgml," 2014. 